Acta Veterinaria Hungarica 62 (2), pp. 243-256 (2014)

DOI: 10.1556/AVet 2013.051

First published online 11 December 2013

\title{
DEVELOPMENT OF A NOVEL IMMUNOPEROXIDASE MONOLAYER ASSAY FOR DETECTION OF SWINE HEPATITIS E VIRUS ANTIBODIES BASED ON STABLE CELL LINES EXPRESSING THE ORF3 PROTEIN
}

\author{
Huanbin LIANG ${ }^{\dagger}$, Heng WANG ${ }^{\dagger *}$, Liangquan ZHANG ${ }^{\dagger}$, Honglang GU and Guihong ZHANG \\ MOA Key Laboratory of Animal Vaccine Development, College of Veterinary \\ Medicine, South China Agricultural University, 483 Wushan Road, Tianhe District, \\ Guangzhou 510642, China
}

(Received 18 January 2013; accepted 2 April 2013)

\begin{abstract}
Hepatitis E virus (HEV) strains are classified into 4 genotypes by nucleotide sequencing. Genotypes 3 and 4 infect humans and animals via HEVcontaminated food or water. HEV RNA was detected by PCR and antibodies were detected by ELISA. Since human studies showed that HEV IgG antibodies in sera can persist for extended periods, diagnosis of HEV infection in swine or humans is mainly based on serological detection using commercial ELISA kits. However, there is no supplemental method to verify ELISA results. Hence, we developed a novel method used for mutual correction of these common processes. Here, a modified stable HepG2 cell line was transfected with pcDNA3.1-ORF3 to express the swine HEV ORF3 protein. Based on this cell line, a novel immunoperoxidase monolayer assay (IPMA) was developed to detect antibodies against HEV. The results show that this method has good specificity, sensitivity and repeatability. When used to investigate 141 porcine serum samples, the IPMA had a coincidence rate of $92.2 \%$ with a commercial ELISA kit. The established IPMA described herein is valuable as a supplemental method to ELISA and can differentiate infections by HEV and other viruses.
\end{abstract}

Key words: Hepatitis E virus (HEV), immunoperoxidase monolayer assay (IPMA), stable expressing cell line, ORF3

Hepatitis E virus (HEV) is an important zoonotic agent worldwide and leads to severe hepatitis E outbreaks in Asia and Africa (Cooper et al., 2005). In the developing countries, hepatitis E mostly occurs as a waterborne disease associated with contaminated water and poor sanitation conditions. However, acute hepatitis E also spreads sporadically in the industrialised countries (Purcell and Emerson, 2008).

\footnotetext{
${ }^{\dagger}$ Equally contributing authors

"Corresponding authors; E-mails: guihongzh@scau.edu.cn; wangheng2009@scau.edu.cn; Phone: 0086 (020) 852-80242; Fax: 0086 (020) 852-80242
} 
Phylogenetic tree analysis has shown that HEV has four genotypes that present different pathogenicities. Genotype 1 spreads throughout Africa and Asia, whereas genotype 2 is epidemic in Mexico, Nigeria and Chad. Both are prevalent in hyperendemic regions and cause severe liver disease in humans, but they cannot cross the species barrier. On the contrary, although genotypes 3 and 4 cause mild hepatitis, they are regarded as zoonotic pathogens of swine and other mammals, which can be transmitted to humans and cause autochthonous acute HEV infections. Genotype 3 is prevalent throughout the USA, South America, Europe, Australasia and Japan, while genotype 4 mainly circulates in China, Japan, and Vietnam (Lu et al., 2006; Sarangi and Srivastava, 2011).

The HEV genome is a linear, single-stranded, positive sense RNA of $7.2 \mathrm{~kb}$ that contains three open reading frames (ORFs) (Reyes et al., 1990; Tam et al., 1991). ORF1 encodes a non-structural polyprotein essential for viral replication. ORF2 encodes a 660-amino-acid (aa) viral capsid protein that includes immunodominant epitopes used for diagnosis (Zhang et al., 2008; Osterman et al., 2012). ORF3 encodes a very small cytoskeleton phosphoprotein with putative regulatory functions (Chandra et al., 2008) and is essential for viral release from infected cells (Yamada et al., 2009). Previous studies strongly suggested that some ORF3 peptides were specific and highly sensitive to swine HEV (swHEV) and could be used as diagnostic targets to detect specific antibodies against HEV in serum samples (Zhao et al., 2009).

Since HEV infection of swine is always asymptomatic, serodiagnosis or detection of HEV RNA is mainly used in laboratories to investigate the prevalence of HEV infection in swine (Jimenez de Oya et al., 2009; Peralta et al., 2009). Recently, specific primers have been designed and sensitive reverse transcription-polymerase chain reaction (RT-PCR) and nested RT-PCR have been developed in independent laboratories to detect HEV (Ward et al., 2009). Furthermore, commercial enzyme-linked immunosorbent assay (ELISA) kits are widely used to detect anti-HEV immunoglobulin G (IgG) or IgM antibodies (Meng et al., 2002). Because of the shortage of appropriate supplemental methods, these commonly used test methods have not been validated. Thus, new methods are needed for mutual correction of these common tests. The immunoperoxidase monolayer assay (IPMA) has been developed to detect antibodies against some other swine viruses, such as porcine reproductive and respiratory syndrome virus (PRRSV) and swine influenza A virus (SIV) (Houben et al., 1995; Direksin et al., 2002). However, an IPMA for swine HEV does not exist, as transient viral transfection methods into mammalian cell lines are needed to develop an IPMA (Direksin et al., 2002; Hornyák et al., 2004). In this study, we modified a traditional method to establish a stable expression cell line to express swHEV ORF3 proteins in order to obtain a useful IPMA for screening antibodies against HEV in sera. 


\section{Materials and methods}

Bacteria, viruses and cells

HepG2 cells, E. coli DH5 $\alpha$ clonal strains, an HEV SS19 (GenBank accession number: JX855794) isolate of genotype 4, and reference sera against PRRSV, foot and mouth disease virus (FMDV), classical swine fever virus (CSFV), porcine circovirus type 2 (PCV2), porcine pseudorabies virus (PRV), porcine parvovirus (PPV), Japanese encephalitis virus (JEV) and H3 subtype SIV were all provided by MOA Key Laboratory of Animal Vaccine Development (College of Veterinary Medicine, South China Agricultural University, Guangzhou, China). HepG2 cells were grown in Dulbecco's modified Eagle's medium (DMEM) supplemented with 10\% fetal bovine serum (FBS), $2 \mathrm{mM} \mathrm{L-}$ glutamine, $100 \mathrm{U}$ of penicillin $\mathrm{mL}^{-1}$ and $100 \mu \mathrm{g}$ of streptomycin $\mathrm{mL}^{-1}$.

\section{ORF3 amplification and recombinant plasmid construction}

For amplification of the ORF3 gene of the HEV SS19 isolate, sense (5'CCCAAGCTTATGGAGATGCCACCATGCG-3') and antisense primers (5'CCGGATATCTACGGCGAAGCCCCAGC-3') were designed based on the sequence of the HEV SS19 isolate. The underlined parts of the primer sequences represent restriction enzyme sites HindIII and EcoRV, respectively. The total viral RNA was extracted using Trizol (Invitrogen, Carlsbad, CA, USA) according to the manufacturer's instructions. Reverse transcription was performed at $42{ }^{\circ} \mathrm{C}$ for 60 min using $9.5 \mu \mathrm{L}$ of total RNA combined with $0.5 \mu \mathrm{L}$ of RNase inhibitor (20 U/Ml), $4.0 \mu \mathrm{L}$ of $5 \times$ avian myeloblastosis virus reverse transcriptase (AMVRT) buffer, $4.0 \mu \mathrm{L}$ of dNTPs (2.5 mmol each), 1.0 of AMV, and $1.0 \mu \mathrm{L}$ of reverse transcription primers (R:O). The amplification was performed in a $100-\mu \mathrm{L}$ reaction mixture containing $2.0 \mu \mathrm{L} \mathrm{MgSO}_{4}(50 \mathrm{mM}), 10.0 \mu \mathrm{L}$ of $10 \times \mathrm{Pfx}$ buffer,

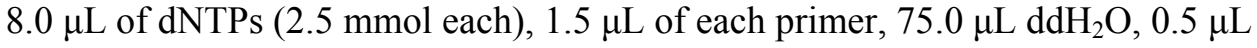
of Pfx DNA polymerase $(2.5 \mathrm{U} / \mu \mathrm{L})$ and $5.0 \mu \mathrm{L}$ of cDNA. The PCR parameters included $95{ }^{\circ} \mathrm{C}$ for $4 \mathrm{~min}, 30$ cycles at $94^{\circ} \mathrm{C}$ for $1 \mathrm{~min}, 58^{\circ} \mathrm{C}$ for $30 \mathrm{~s}, 68^{\circ} \mathrm{C}$ for $45 \mathrm{~s}$, and a final extension of $10 \mathrm{~min}$ at $72^{\circ} \mathrm{C}$. The enzyme-digested PCR products were cloned into the HindIII:EcoRV site of vector pcDNA3.1(+)/myc-His A (Invitrogen, Carlsbad, CA, USA). The recombinant plasmid was named pcDNA3.1-ORF3.

\section{Transfection of HepG2 cells and screening for stable expression in cell lines}

The G418 culture medium was diluted from 1000 to $100 \mu \mathrm{g} / \mathrm{mL}$ in $100 \mu \mathrm{g} / \mathrm{mL}$ increments to construct the selective medium. A HepG2 cell suspension was prepared and inoculated into a 96-well culture plate. After $6 \mathrm{~h}$ of incubation, the culture medium was discarded and the cells were washed with sterile phosphatebuffered saline (PBS) of $\mathrm{pH} \mathrm{7.2,} \mathrm{then} \mathrm{different} \mathrm{concentrations} \mathrm{of} \mathrm{screening} \mathrm{cul-}$ 
ture medium were added into each well with 3 groups of parallel repeats of each concentration. Depending on the colour of the medium and the cell growth conditions, the culture medium was changed every 3-5 days over 10-14 days and the one which killed all cells with a minimal G418 concentration was the optimal screening concentration.

HepG2 cells were inoculated into 12 -well plates $\left(1 \times 10^{5} /\right.$ well $)$ the day before transfection. Prior to transfection, cells were washed twice with OptiMEM (Gibco-Life Technologies, Grand Island, NY, USA). Serum-free Opti-MEM I Medium (Invitrogen) and pcDNA3.1-ORF3 were mixed in a tube. Then, Lipofectamine 2000 (Invitrogen) was mixed with the serum-free Opti-MEM I Medium. After $5 \mathrm{~min}$, the transfection mixture was mixed with the OptiMEM-liposome mixture, which was added to the cell culture medium. After $20 \mathrm{~min}$, the culture was incubated at $34.5{ }^{\circ} \mathrm{C}$ in a humidified atmosphere of $5 \% \mathrm{CO}_{2}$ for $4-6 \mathrm{~h}$. Then, the mixture was aspirated and fresh medium was added and incubated at $34.5^{\circ} \mathrm{C}$ for 24-48 h. Passaged cells were planted into fresh growth medium with G418 at an optimal concentration until the cells reached $50-70 \%$ confluence. Based on medium colour and cell growth, G418 should be added to maintain screening. After selection for 10-14 days, G418-resistant clones were selected using an expanding culture. Cells were diluted with culture medium to $1 / 10 \mu \mathrm{L}$ and inoculated in 48-well plates for proliferation and the stably expressed ORF3-transfected cells were selected. The modified cell line was named HepG2-ORF3.

Detection of eukaryotic expression via RT-PCR and an immunofluorescence assay (IFA)

In order to detect the ORF3 mRNA expression in HepG2-ORF3 cells by RT-PCR, total RNA was extracted from HepG2 cells. Single-stranded cDNA was synthesised from total RNA using AMV-RT (TaKaRa, Tokyo, Japan). PCR was carried out using the primers for ORF3 to produce a 345-bp product.

The IFA was used to detect the expression of specific ORF3 HEV proteins in HepG2 cells. Briefly, cells were fixed for 20 min with methanol at $-20^{\circ} \mathrm{C}$. After washing with PBS, cells were incubated with anti-His antibody (Sigma, USA) at $37^{\circ} \mathrm{C}$ for $1 \mathrm{~h}$, washed with PBS three times, and then incubated with antimouse IgG/DyLight 488 for $1 \mathrm{~h}$ at $37^{\circ} \mathrm{C}$ in the dark. After washing, the percentage of positive cells was evaluated via fluorescence microscopy.

\section{Growth curves of HepG2-ORF3 transfected cells}

To determine the optimal growth conditions of pcDNA3.1-ORF3 in HepG2 cells, the 3-(4,5 dimethylthiozol-2-yl)-2,5-diphenyl-tetrazolium bromide (MTT) assay was used. An experimental group with HepG2-ORF3-transfected cells and a control group with non-transfected cells were established. The above cells were inoculated in 96-well plates and the total cell number was quantified 
daily using the MTT assay. Next, $20 \mu \mathrm{L}$ of MTT $(5 \mathrm{mg} / \mathrm{mL})$ was added to each well and incubated at $37^{\circ} \mathrm{C}$ for $4 \mathrm{~h}$. After discarding the supernatant, $100 \mu \mathrm{L}$ of dimethyl sulphoxide was added to each well. The cellular growth conditions were monitored using a microplate reader with a $490-\mathrm{nm}$ filter and expressed as optical density (OD).

\section{Development of an IPMA for HEV diagnosis}

Before performing the IPMA assay, suspensions of HepG2-ORF3 and HepG2 cells were fixed in 96-well plates, with HepG2-ORF3 cells in columns 1, 3, 5, 7, 9 and 11 and HepG2 cells in columns 2, 4, 6, 8, 10 and 12. Cells were incubated at $37{ }^{\circ} \mathrm{C}$ in a humidified atmosphere of $5 \% \mathrm{CO}_{2}$ and then acetone at $-20{ }^{\circ} \mathrm{C}$ was added to fix the cells in monolayers.

Matrix analysis was applied to determine the optimal reaction conditions of the IPMA. The positive and negative serum samples from swine identified by a commercial ELISA kit were diluted using a double dilution method with a starting dilution of 1:25. Horseradish peroxidase-labelled protein A of Staphylococcus aureus (HRP-SpA) as the reference antiserum was diluted to 1:500, 1:1000, 1:2000 and 1:3000 before use. The stably expressed HepG2-ORF3 cells were fixed for $10 \mathrm{~min}$ at $4{ }^{\circ} \mathrm{C}$ using cold $4 \%$ paraformaldehyde in PBS and washed three times with PBS. Serum samples were diluted in PBS $+0.1 \%$ Tween-20 (PBST) with $0.5 \%$ gelatine and then added to the wells, incubated at $37^{\circ} \mathrm{C}$ for $1 \mathrm{~h}$, and washed three times with PBST. Different concentrations of HRP-SpA were added to each well $(100 \mu \mathrm{L} /$ well $)$ and incubated for $1 \mathrm{~h}$ at $37^{\circ} \mathrm{C}$. After washing three times with PBST, 3-amino-9-ethyl-carbazole (AEC) substrate was prepared according to the manufacturer's instructions, added to the wells, and incubated at $37^{\circ} \mathrm{C}$ for $15 \mathrm{~min}$. After another washing, the cells were dried and then examined under an inverted microscope. Wells with HepG2ORF3 cells incubated with negative sera and wells with only HepG2 cells remain unstained, whereas wells containing HepG2-ORF3 cells and incubated with positive sera were stained reddish-brown.

\section{Characteristic analysis of the IPMA assay}

To test the specificity of the IPMA, reference sera against PRRSV, FMDV, CSFV, PCV2, PRV, PPV, JEV and H3 subtype SIV were examined to determine cross-reactions of the HepG2-ORF3 cell line. Positive sera of antiswHEV antibody were diluted using a double dilution method with a starting concentration of 1:25 to determine the sensitivity of the IPMA.

To determine the repeatability of this method, sera obtained from the same or different batches were tested. In total, 141 random swine serum samples were examined via IPMA and ELISA (Wantai Biological Pharmacy Co., Beijing, China) to compare the positive rates and calculate the total coincidence rate. 


\section{Results}

\section{Amplification of ORF3 and construction of pcDNA3.1-ORF3}

The fragment from HEV ORF3 was PCR-amplified with primers containing HindIII and EcoRV sites. PCR products were analysed by agarose gel electrophoresis and the results indicated that a 345-bp fragment of ORF3 was successfully obtained. The enzyme-digested PCR products were inserted into the expression vector pcDNA3.1(+)/myc-His A. The correctness of the insert was confirmed by agarose gel electrophoresis and DNA sequencing (Fig. 1A).

\section{Eukaryotic expression and growth curve assays of HepG2-ORF3}

To confirm the expression of ORF3 mRNA in HepG2 cells, total RNA was extracted from G418-resistant monoclonal cells. Three rRNA bands (28S, $18 \mathrm{~S}$ and $5 \mathrm{~S}$ ) could be clearly seen in the agarose gels (Fig. 1B). RT-PCR results showed that the predicted 345 bp fragment was obtained (Fig. 1C).

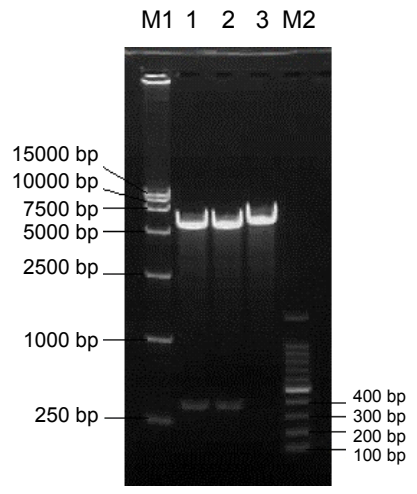

A

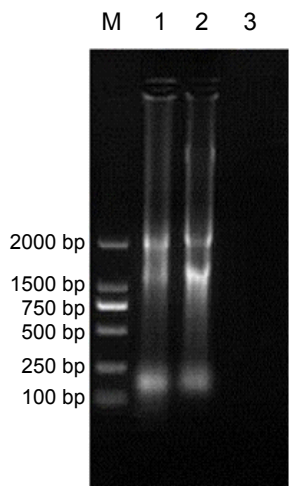

B

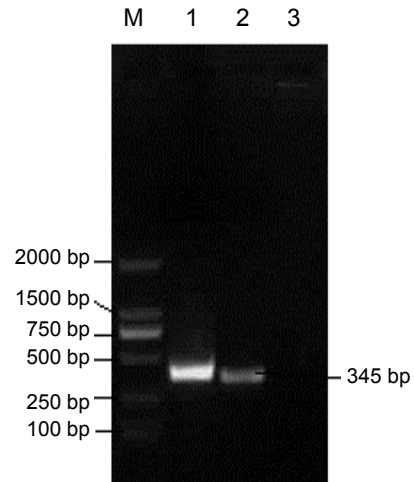

C

Fig. 1. Results of agarose gel electrophoresis detection. (A) The recombinant plasmid pCDNA3.1ORF3 was digested with HindIII:EcoRV. Agarose gel electrophoresis results showed that fragments $>345 \mathrm{bp}$ were obtained in lanes 1 and 2. Lane M1, DNA 15,000 marker; lanes 1-2, pCDNA3.1-ORF3 double enzyme digest; lane 3, pCDNA3.1-ORF3 enzyme digest; lane M2, DNA 100 marker. (B). Total RNA was obtained from G418-resistant monoclonal cells and digested by

DNase I (RNase free). Lane M, DNA 2000 marker; lanes 1-2, 3 rRNA bands extracted from monoclonal cells visualised via agarose gel electrophoresis; lane 3, blank control. (C) RT-PCR detection of HepG2-ORF3 cells to confirm the expression of HEV ORF3. Results showed that the predicted fragments of $345 \mathrm{bp}$ were obtained as expected. Lane M, DNA 2000 marker; lanes 1-2, RT-PCR detection of cells transfected with pCDNA3.1-ORF3 cell; lane 3, RT-PCR detection of cells transfected with pCDNA3.1-ORF3 cell treated with DNase for contrast

An IFA was performed to confirm ORF3 expression in HepG2 cells. Results demonstrated that the HEV ORF3 protein was expressed in HepG2 cells. On the contrary, no fluorescence was detected in the negative control cells (Fig. 2). 
There were no obvious differences in growth conditions between the experimental and control groups. Furthermore, there were no cytopathic effects on the HepG2 cells (data not shown).
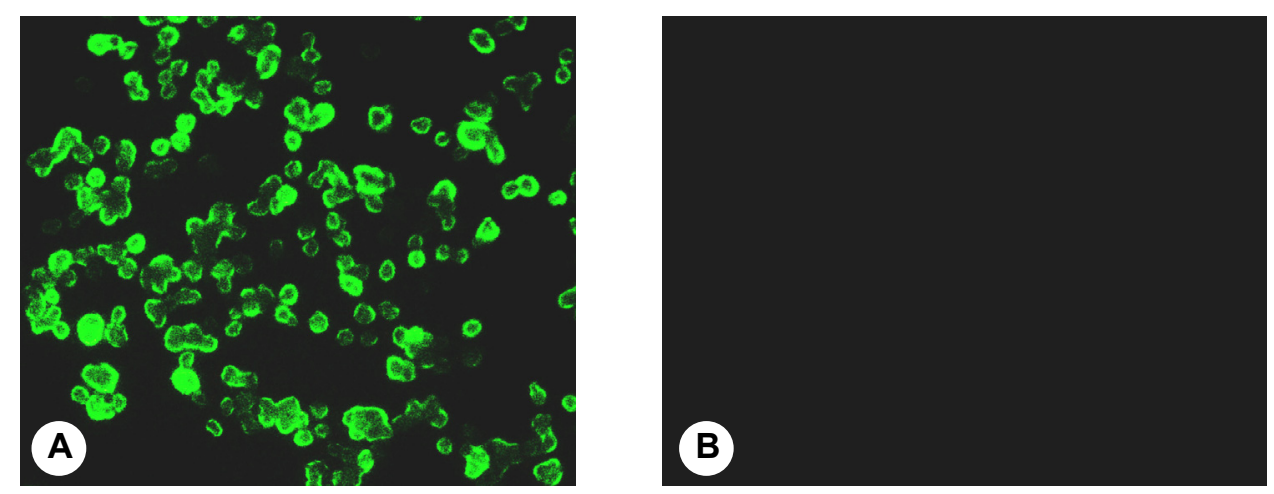

Fig. 2. Expression of swHEV ORF3 in HepG2 cells via IFA $(\times 20)$. (A) Green fluorescence is seen in HepG2 cells transfected with recombinant plasmid pCDNA3.1-ORF3. (B) Negative control cells transfected with pcDNA3.1(+)/myc-His A

The MTT assay was used to investigate the effects of the recombinant plasmid pcDNA3.1-ORF3 on HepG2 cell proliferation. Our results indicated that HepG2-ORF3-transfected cells maintained exponential growth for 1-3 days and then reached a plateau (data not shown).

\section{Characteristics analysis of IPMA for HEV using the HepG2-ORF3 cell line}

Matrix analysis was used to determine the optimal reaction conditions. Our results showed that the dilution of HRP-SpA should be 1:3000 and the optimum concentration of sera was 1:100. Inverted microscopy showed that wells containing HepG2-ORF3 cells and incubated with positive sera were stained a reddish-brown colour (Figs 3A and 3C). However, wells with HepG2-ORF3 cells incubated with negative sera and those containing only HepG2 cells remained unstained (Figs 3B and 5D).

To evaluate the specificity of this method, reference sera against PRRSV, FMDV, CSFV, PCV2, PRV, PPV, JEV and H3 subtype SIV were examined via IPMA using the HepG2-ORF3 cell line. No serological cross-reactions were present and the specificity was confirmed (Fig. 4).

Results of the sensitivity test revealed that even if incubated with a serum sample at a dilution lower than 1:200, specific cell staining could be clearly seen (Fig. 5). 

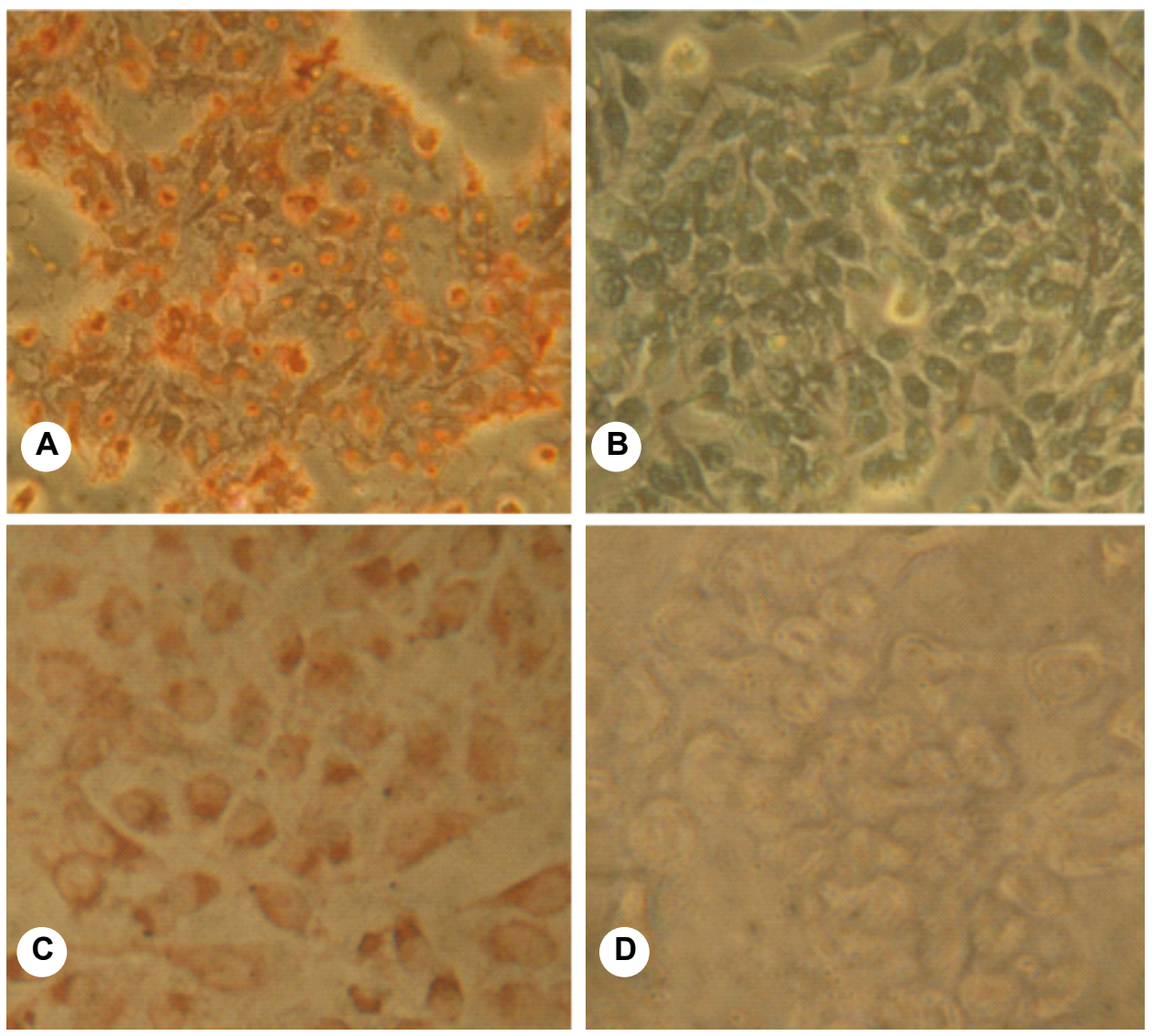

Fig. 3. Colour changes of IPMA between the experimental and control groups. HepG2-ORF3 cells were passaged after transfection and cultured in 96-well plates for detection using positive swHEV sera as the primary antibody. (A) HepG2-ORF3 cells incubated with swHEV positive sera $(\times 20)$;

(B) HepG2 cells incubated with swHEV positive sera $(\times 20)$; (C) HepG2-ORF3 cells incubated with swHEV positive sera $(\times 40)$; and (D) HepG2 cells incubated with swHEV positive sera $(\times 40)$. A reddish-brown colour could be seen in the experimental group

To test the repeatability of the IPMA assay, three plates were assembled from the same batch and three from different batches. All of the results were consistent and revealed that there were no differences between the same or different batches (data not shown).

Comparison tests between the ELISA and IPMA using the HepG2-ORF3 cell line

The positivity rate of the IPMA using the modified cell line was compared with the ELISA results. A total of 141 random swine serum samples were examined by both methods (Table 1). The results showed that there were 127 positive 
and 14 negative serum samples detected by the IPMA, whereas the ELISA detected 124 positive and 17 negative serum samples. Hence, the IPMA was more specific and much more sensitive than the ELISA. Meanwhile, the total coincidence rate between the methods was $92.2 \%$, suggesting that the IPMA developed in this study can be used as an alternative test for swine HEV.

\section{Discussion}

Major antigenic epitopes of HEV contained in ORF2 and ORF3 (Yarbough et al., 1991; Khudyakov Yu et al., 1994) could be used as the ideal diagnostic targets for HEV detection (Dawson et al., 1992). ORF2 is located at the 3' end of the genome and encodes a capsid protein that encapsulates the viral RNA genome and contains an endoplasmic reticulum (ER) signal peptide and 3 putative N-glycosylation sites (Graff et al., 2008), which have been the focus of studies of antigenic sites (Ma et al., 2009; Pan et al., 2010). However, recent studies compared the polypeptide ends of the ORF1, ORF2 and ORF3 proteins. The results demonstrated that the ORF3 protein had high specificity and sensitivity to detect anti-HEV IgG and IgM antibodies and was expected to be a potential diagnostic target (Kai et al., 2009). The ORF3 peptides should provide efficient development of an accurate and rapid swHEV detection method. The ORF3 fragment of swHEV strain SS19 was used as an antigen to establish an IPMA to detect specific swHEV antibodies in this study. Customarily, an IPMA is used to monitor antigen by inoculating viruses into cells (Khudyakov Yu et al., 1994; Direksin et al., 2002; Guedes et al., 2002), which involves complicated procedures and unstable antigen content. A recent study suggested that cells stably expressing the major viral antigen could be used for IPMA (Sagong et al., 2010). In the present study, we developed an IPMA for the detection of swHEV antibodies using modified HepG2 cell lines that stably expressed the ORF3 protein as a diagnostic target.

Current ELISA kits for the detection of antibodies were compared with IPMAs in many studies and the results were diverse. Soliman et al. (1997) and Houben et al. (1995) found that the IPMA was less sensitive than the ELISA. In contrast, Yoon et al. (1995) reported that the IPMA performed slightly better than a commercial ELISA kit to monitor the appearance and longevity of antibody responses in experimentally infected animals. However, the IPMA based on stable expression in cell lines established in the present study was convenient and repeatable. The specificity of this method was confirmed by antibody reactions against other viruses. Furthermore, a total of 141 swine serum samples were simultaneously subjected to IPMA and ELISA and the results indicated that the total coincidence rate between the two methods was $92.2 \%$. 

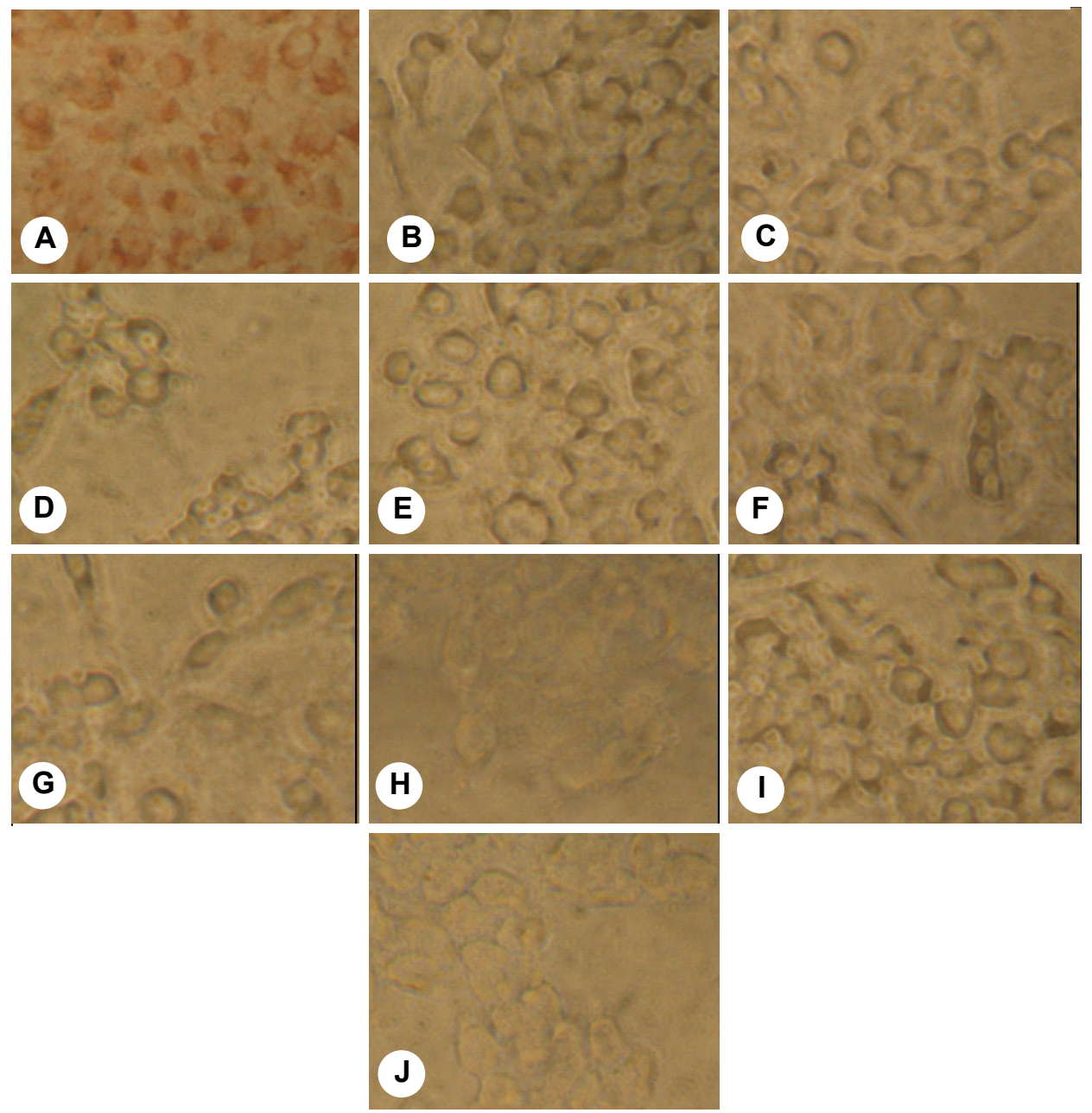

Fig. 4. Specificity testing of the IPMA. Pictures A-I are the results of HepG2-ORF3 cells reacted with the reference serum against HEV, RRSV, FMDV, CSFV, PCV2, PRV, PPV, JEV and H3 subtype SIV, respectively. Picture J was the blank result of HepG2-ORF3 cells inoculated with PBS. Results showed that a reddish-brown colour was only seen in Picture A

Above all, we developed a stable HepG2 cell line constitutively expressing the specific swHEV ORF3 protein. The modified cell line showed good reactivity with specific antibodies against swHEV. Thus, the IPMA based on this cell line offers an alternative method to detect swHEV. Further, the colour indicating a positive reaction in the IPMA was stable for several months; therefore, it can provide a lasting record of test results. Although this method seemed to be somewhat subjective, it was convenient and simple. In contrast with the ELISA, the present IPMA did not require highly purified antigens and was relatively lower 

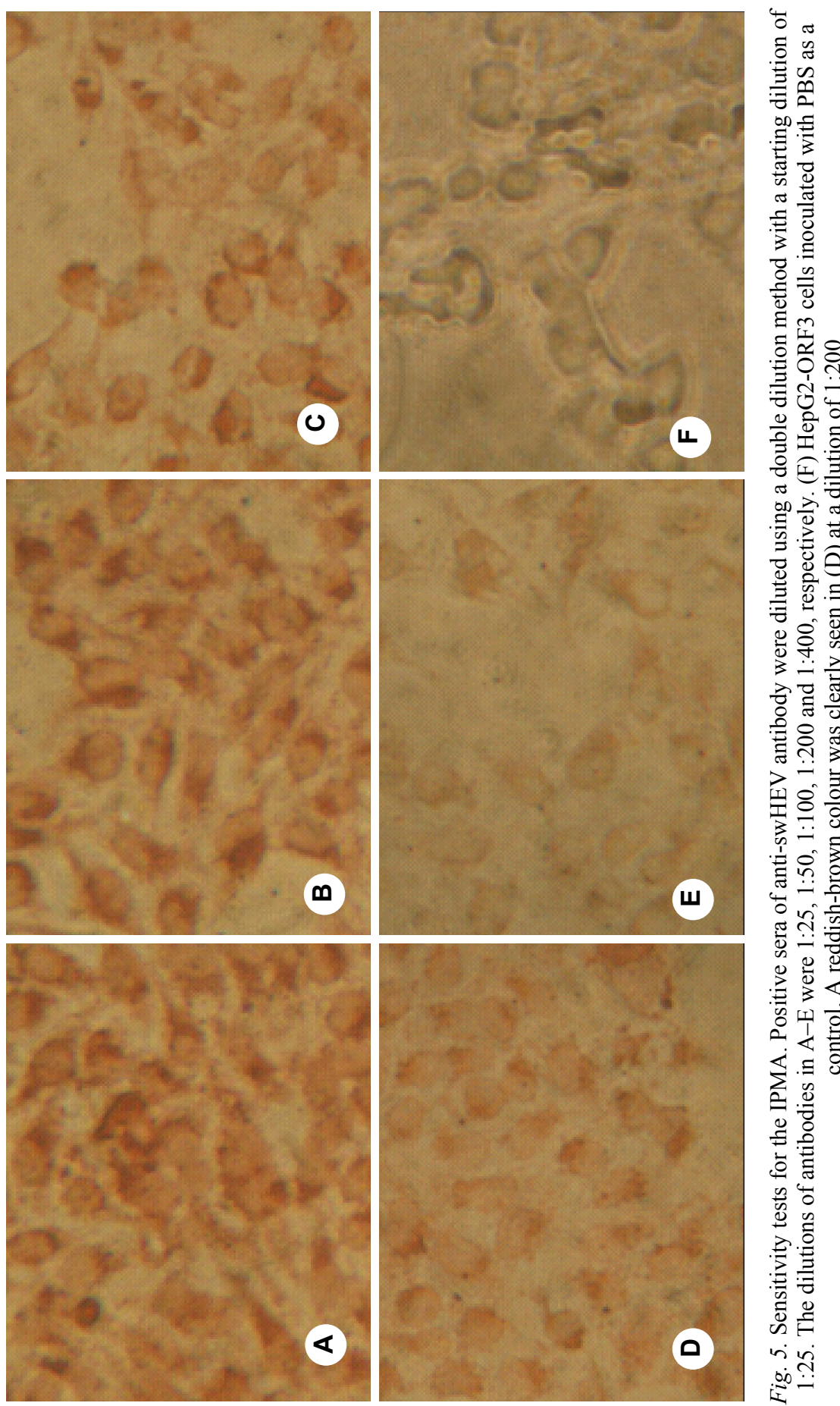

Acta Veterinaria Hungarica 62, 2014 
in cost compared with the expensive commercial ELISA kit. Furthermore, when performing serological and epidemiological surveys, the IPMA presents a beneficial supplement to an ELISA.

Table 1

Compliance test between IPMA and ELISA

\begin{tabular}{|c|c|c|c|c|}
\hline \multirow{2}{*}{\multicolumn{2}{|c|}{ Methods }} & \multicolumn{2}{|c|}{ ELISA } & \multirow{2}{*}{$\begin{array}{l}\text { Total no. detected } \\
\text { by IPMA }\end{array}$} \\
\hline & & + & - & \\
\hline \multirow{2}{*}{ IPMA } & + & 120 & 7 & 127 \\
\hline & - & 4 & 10 & 14 \\
\hline \multicolumn{2}{|c|}{ Total no. detected by ELISA } & 124 & 17 & 141 \\
\hline \multicolumn{2}{|c|}{ Total coincidence rate, $\%$} & & 92.2 & \\
\hline
\end{tabular}

+: positive no., -: negative no.

In conclusion, the established IPMA described in this paper is valuable for detecting and differentiating HEV infections from other commonly occurring viruses. Meanwhile, the present methodology has the potential to develop a stable expressing cell-line-based novel detection technique for other pathogens.

\section{Acknowledgements}

This work was supported by the Ph.D. Programs Foundation of Ministry of Education of China (No. 20104404110009 and No. 20114404120010), the Industry Technology System of Modern Agriculture Construction Fund (No. CARS-36) and a grant from the Department of Education of Guangdong Province (No. 2012LYM_0031).

\section{References}

Chandra, V., Taneja, S., Kalia, M. and Jameel, S. (2008): Molecular biology and pathogenesis of hepatitis E virus. J. Biosci. 33, 451-464.

Cooper, K., Huang, F. F., Batista, L., Rayo, C. D., Bezanilla, J. C., Toth, T. E. and Meng, X. J. (2005): Identification of genotype 3 hepatitis E virus (HEV) in serum and fecal samples from pigs in Thailand and Mexico, where genotype 1 and 2 HEV strains are prevalent in the respective human populations. J. Clin. Microbiol. 43, 1684-1688.

Dawson, G. J., Chau, K. H., Cabal, C. M., Yarbough, P. O., Reyes, G. R. and Mushahwar, I. K. (1992): Solid-phase enzyme-linked immunosorbent assay for hepatitis E virus IgG and IgM antibodies utilizing recombinant antigens and synthetic peptides. J. Virol. Methods 38, $175-186$.

Direksin, K., Joo, H. and Goyal, S. M. (2002): An immunoperoxidase monolayer assay for the detection of antibodies against swine influenza virus. J. Vet. Diagn. Invest. 14, 169-171. 
Graff, J., Zhou, Y. H., Torian, U., Nguyen, H., St Claire, M., Yu, C., Purcell, R. H. and Emerson, S. U. (2008) Mutations within potential glycosylation sites in the capsid protein of hepatitis E virus prevent the formation of infectious virus particles. J. Virol. 82, 1185-1194.

Guedes, R. M., Gebhart, C. J., Winkelman, N. L. and Mackie-Nuss, R. A. (2002): A comparative study of an indirect fluorescent antibody test and an immunoperoxidase monolayer assay for the diagnosis of porcine proliferative enteropathy. J. Vet. Diagn. Invest. 14, 420-423.

Hornyák, Á., Dénes, B., Szeredi, L., Dencső, L. and Rusvai, M. (2004): Diagnostic application of immunoperoxidase monolayer assay using monoclonal antibodies produced against equine arteritis virus 14-kDa nucleocapsid protein. Hybrid Hybridomics 23, 368-372.

Houben, S., Callebaut, P. and Pensaert, M. B. (1995): Comparative study of a blocking enzymelinked immunosorbent assay and the immunoperoxidase monolayer assay for the detection of antibodies to the porcine reproductive and respiratory syndrome virus in pigs. J. Virol. Methods 51, 125-128.

Jimenez de Oya, N., Galindo, I., Girones, O., Duizer, E., Escribano, J. M. and Saiz, J. C. (2009): Serological immunoassay for detection of hepatitis $\mathrm{E}$ virus on the basis of genotype 3 open reading frame 2 recombinant proteins produced in Trichoplusia ni larvae. J. Clin. Microbiol. 47, 3276-3282.

Kai, J., Ulph, F., Cullinan, T. and Qureshi, N. (2009): Communication of carrier status information following universal newborn screening for sickle cell disorders and cystic fibrosis: qualitative study of experience and practice. Health Technol. Assess. 13, 1-82.

Khudyakov Yu, E., Favorov, M. O., Jue, D. L., Hine, T. K. and Fields, H. A. (1994): Immunodominant antigenic regions in a structural protein of the hepatitis E virus. Virology 198, 390-393.

Lu, L., Li, C. and Hagedorn, C. H. (2006): Phylogenetic analysis of global hepatitis E virus sequences: genetic diversity, subtypes and zoonosis. Rev. Med. Virol. 16, 5-36.

Ma, H., Song, X., Li, Z., Harrison, T. J., Zhang, H., Huang, W., Hao, W., Kong, W. and Wang, Y. (2009): Varying abilities of recombinant polypeptides from different regions of hepatitis $\mathrm{E}$ virus ORF2 and ORF3 to detect anti-HEV immunoglobulin M. J. Med. Virol. 81, 1052-1061.

Meng, X. J., Wiseman, B., Elvinger, F., Guenette, D. K., Toth, T. E., Engle, R. E., Emerson, S. U. and Purcell, R. H. (2002): Prevalence of antibodies to hepatitis E virus in veterinarians working with swine and in normal blood donors in the United States and other countries. J. Clin. Microbiol. 40, 117-122.

Osterman, A., Vizoso Pinto, M. G., Haase, R., Nitschko, H., Jager, S., Sander, M., Motz, M., Mohn, U. and Baiker, A. (2012): Systematic screening for novel, serologically reactive Hepatitis E virus epitopes. Virol. J. 9, 28.

Pan, J. S., Zhang, K., Zhou, J., Wu, C., Zhuang, H. and Zhou, Y. H. (2010): Application of truncated immunodominant polypeptide from hepatitis E virus (HEV) ORF2 in an assay to exclude nonspecific binding in detecting anti-HEV immunoglobulin M. J. Clin. Microbiol. 48, 779-784.

Peralta, B., Casas, M., de Deus, N., Martin, M., Ortuno, A., Perez-Martin, E., Pina, S. and Mateu, E. (2009): Anti-HEV antibodies in domestic animal species and rodents from Spain using a genotype 3-based ELISA. Vet. Microbiol. 137, 66-73.

Purcell, R. H. and Emerson, S. U. (2008): Hepatitis E: an emerging awareness of an old disease. J. Hepatol. 48, 494-503.

Reyes, G. R., Purdy, M. A., Kim, J. P., Luk, K. C., Young, L. M., Fry, K. E. and Bradley, D. W. (1990): Isolation of a cDNA from the virus responsible for enterically transmitted non-A, non-B hepatitis. Science 247, 1335-1339.

Sagong, M., Park, C. K., Kim, S. H., Moon, S. U., Cho, S. C. and Lee, C. (2010): Development and characterization of stable cell lines constitutively expressing the porcine reproductive and respiratory syndrome virus nucleocapsid protein. J. Vet. Sci. 11, 169-171.

Sarangi, A. N. and Srivastava, S. (2011): Phylogenetic analysis of swine \& human hepatitis E virus. Indian J. Med. Res. 133, 548-549. 
Soliman, A. K., Watts, D. M., Salib, A. W., Shehata, A. E., Arthur, R. R. and Botros, B. A. (1997): Application of an immunoperoxidase monolayer assay for the detection of arboviral antibodies. J. Virol. Methods 65, 147-151.

Tam, A. W., Smith, M. M., Guerra, M. E., Huang, C. C., Bradley, D. W., Fry, K. E. and Reyes, G. R. (1991): Hepatitis E virus (HEV): molecular cloning and sequencing of the full-length viral genome. Virology 185, 120-131.

Ward, P., Poitras, E., Leblanc, D., Letellier, A., Brassard, J., Plante, D. and Houde, A. (2009): Comparative analysis of different TaqMan real-time RT-PCR assays for the detection of swine Hepatitis E virus and integration of feline calicivirus as internal control. J. Appl. Microbiol. 106, 1360-1369.

Yamada, K., Takahashi, M., Hoshino, Y., Takahashi, H., Ichiyama, K., Nagashima, S., Tanaka, T. and Okamoto, H. (2009): ORF3 protein of hepatitis E virus is essential for virion release from infected cells. J. Gen. Virol. 90, 1880-1891.

Yarbough, P. O., Tam, A. W., Fry, K. E., Krawczynski, K., McCaustland, K. A., Bradley, D. W. and Reyes, G. R. (1991): Hepatitis E virus: identification of type-common epitopes. J. Virol. 65, 5790-5797.

Yoon, K. J., Zimmerman, J. J., Swenson, S. L., McGinley, M. J., Eernisse, K. A., Brevik, A., Rhinehart, L. L., Frey, M. L., Hill, H. T. and Platt, K. B. (1995): Characterization of the humoral immune response to porcine reproductive and respiratory syndrome (PRRS) virus infection. J. Vet. Diagn. Invest. 7, 305-312.

Zhang, H., Dai, X., Shan, X. and Meng, J. (2008): The Leu477 and Leu613 of ORF2-encoded protein are critical in forming neutralization antigenic epitope of hepatitis E virus genotype 4. Cell Mol. Immunol. 5, 447-456.

Zhao, K., Liu, Q., Yu, R., Li, Z., Li, J., Zhu, H., Wu, X., Tan, F., Wang, J. and Tang, X. (2009): Screening of specific diagnostic peptides of swine hepatitis E virus. Virol. J. 6, 186. 